NBER WORKING PAPER SERIES

TAKING STOCK OF THE EVIDENCE ON MICRO-FINANCIAL INTERVENTIONS

Francisco J. Buera

Joseph P. Kaboski

Yongseok Shin

Working Paper 22674

http://www.nber.org/papers/w22674

\author{
NATIONAL BUREAU OF ECONOMIC RESEARCH \\ 1050 Massachusetts Avenue \\ Cambridge, MA 02138 \\ September 2016
}

We thank our discussant, Stephen Smith, Oriana Bandiera, and the conference participants for useful comments and suggestions. All errors remain our own. The views expressed here do not necessarily reflect the position of the Federal Reserve Banks of Chicago and St. Louis, the Federal Reserve System, or the National Bureau of Economic Research.

At least one co-author has disclosed a financial relationship of potential relevance for this research. Further information is available online at http://www.nber.org/papers/w22674.ack

NBER working papers are circulated for discussion and comment purposes. They have not been peer-reviewed or been subject to the review by the NBER Board of Directors that accompanies official NBER publications.

(C) 2016 by Francisco J. Buera, Joseph P. Kaboski, and Yongseok Shin. All rights reserved. Short sections of text, not to exceed two paragraphs, may be quoted without explicit permission provided that full credit, including $\odot$ notice, is given to the source. 
Taking Stock of the Evidence on Micro-Financial Interventions

Francisco J. Buera, Joseph P. Kaboski, and Yongseok Shin

NBER Working Paper No. 22674

September 2016

JEL No. O1,O11,012,O16

\section{$\underline{\text { ABSTRACT }}$}

We review the empirical evidence on microfinance and asset grants to the ultra poor or microentrepreneurs, and assess our ability to account for this evidence using quantitative theory. Properly executed, these interventions can help segments of the population increase their income and consumption, but neither the empirical micro nor quantitative macro literatures give much reason to believe that such interventions can lead to wide-scale, transformative impacts akin to escaping aggregate poverty traps.

Francisco J. Buera

Federal Reserve Bank of Chicago 230 South La Salle Street

Chicago, IL 60604

francisco.buera@chi.frb.org

Joseph P. Kaboski

Department of Economics

University of Notre Dame

434 Flanner Hall

Notre Dame, IN 46556

and NBER

jkaboski@nd.edu
Yongseok Shin

Department of Economics

Washington University in St. Louis

One Brookings Drive

St. Louis, MO 63130

and NBER

yshin@wustl.edu 


\title{
Taking Stock of the Evidence on Micro-Financial Interventions*
}

\author{
Francisco J. Buera ${ }^{\dagger} \quad$ Joseph P. Kaboski ${ }^{\ddagger} \quad$ Yongseok Shin $^{\S}$
}

September 2016

\begin{abstract}
We review the empirical evidence on microfinance and asset grants to the ultra poor or microentrepreneurs, and assess our ability to account for this evidence using quantitative theory. Properly executed, these interventions can help segments of the population increase their income and consumption, but neither literature gives much reason to believe that such interventions can lead to wide-scale, transformative impacts akin to escaping aggregate poverty traps.
\end{abstract}

\section{Introduction}

The past decade of empirical development research has produced a host of highly insightful, well-identified evaluations of the impacts of micro-financial interventions. These interventions include microcredit programs, asset grants to micro-entrepreneurs, and small asset transfers to the very poor, regardless of their entrepreneurial status. The aim of this paper is to take stock of the state of our knowledge.

The process involves at least two parts. A necessary part of taking stock is the review of these findings that attempts to crystallize the salient patterns. Another equally necessary part of taking stock is to assess our understanding of these empirical patterns through the lens of economic theory. Reflecting on the policy lessons of the East Asian miracles, Robert E. Lucas, Jr. once observed "If we understand the process of economic growth - or of anything else - we ought to be capable of demonstrating this knowledge by creating it in these pen and paper (and computer-equipped) laboratories of ours. If we know what an economic miracle

*We thank our discussant, Stephen Smith, Oriana Bandiera, and the conference participants for useful comments and suggestions. All errors remain our own. The views expressed here do not necessarily reflect the position of the Federal Reserve Banks of Chicago and St. Louis or the Federal Reserve System.

${ }^{\dagger}$ Federal Reserve Bank of Chicago

${ }^{\ddagger}$ University of Notre Dame and NBER

${ }^{\S}$ Washington University in St. Louis, Federal Reserve Bank of St. Louis and NBER 
is, we ought to be able to make one" (Lucas, 1993, p. 271). The same is true for poverty traps and financial interventions. If we truly understand why an intervention works, we ought to be able to recreate the empirical patterns in our theories. Such an understanding is necessary to design our policy interventions, apply them with confidence in new contexts, and make projections for larger-scale programs that will have macroeconomic consequences.

Toward the first step, this essay reviews the lessons from the empirical literature on micro interventions. At least three general lessons arise consistently. First, no policies produce large scale miracle escapes from poverty traps. That is, although some of the policies have led to sustained gains, none has been shown to lead to permanent increases in income or consumption well beyond poverty levels nor to extended and sizable increases in the rate of growth of income, consumption, and capital that predict such escapes. Second, take-up rates for microcredit are typically low, while those of asset transfer programs are understandably much higher. Third, heterogeneous responses to policies are evident in almost all studies, where impacts vary by initial wealth, size of intervention, gender, ability, entrepreneurial status, financial access, and time frame. Variation in measurement and context (e.g., rural vs. urban, the degree of pre-existing financial development) may also play a role.

The most interesting patterns emerge from a comparison across interventions. Although individual-level microcredit interventions can lead to increases in credit, entrepreneurial activity, and investments, they have been much less successful in leading to higher income or consumption. Among these interventions, only the two studies of village funds microcredit interventions uncovered gains to income and possibly consumption. They often show relatively larger impacts on existing or marginal entrepreneurs. Small asset grants of less than $\$ 200$ at purchasing power parity (PPP, hereafter) to entrepreneurs often lead to stronger increases in capital and profits with typically high returns on assets. Grants to "ultra poor" households often have led to changes in income generating activities, higher asset levels and capital, and increases in consumption of up to 30 percent.

The natural question is what leads to such very different outcomes, and what do they say about the relevant economic mechanisms at play. Even to replicate the outcomes of these different policies in varying contexts, we need an understanding of these mechanisms. Lucas (1993, p. 252) is again much more eloquent: "simply advising a society to 'follow the Korean model' is a little like advising an aspiring basketball player to 'follow the Michael Jordan model'. To make use of someone else's successful performance at any task, one needs to be able to break this performance down into its component parts so that one can see what each part contributes to the whole, which aspects of this performance are imitable and, of these, which are worth imitating. One needs, in short, a theory." A purely qualitative theory is useful in terms of organizing ideas and checking the internal consistency of one's reasoning, 
but we also want to know how well such a theory can quantitatively explain our observations, which is undoubtedly a higher hurdle.

Toward the second step, we review existing quantitative theory of financially constrained entrepreneurial decisions. A representative model in this literature incorporates much of what seems a priori essential in the economics involved: ex ante heterogeneity in wealth and ability, entrepreneurial decisions on both the extensive (entry) and intensive margins (scale), stochastic shocks, "necessity" entrepreneurs, and financial constraints that interact with wealth and ability. The combination of heterogeneity, intensive margins, and stochastic shocks provide enough smoothness and mixing so that poverty traps at the level of an individual (where investment decisions and asset and income paths depend critically on initial wealth levels) become irrelevant at the level of the economy (where a unique stationary equilibrium exists). Using this model, we simulate analogs of microcredit interventions and the asset grants targeted toward the poor and small entrepreneurs. Within our microcredit interventions we further vary the interest rates faced by borrowers. Some of these simulations reproduce results from our earlier work (Buera et al., 2012, 2014), while others are unique to this paper.

We show that the model captures many of the qualitative and quantitative patterns observed empirically in the interventions, but we also learn lessons from where it fails. For asset grants, the model shows that marginal entrepreneurs enter, and that capital, income, and consumption increase, while assets tend to decline over time. However, the model does not generate the large increases in income, and we conjecture that the model fails to account for increases in labor supply in certain economic situations (e.g., where market labor is limited for women). Moreover, the training components of such interventions might increase the effective ability of livestock "entrepreneurs", or the real world projects may somehow target the higher ability people (i.e., marginal entrepreneurs). ${ }^{1}$ Indeed, we show that marginal products of capital to poor existing entrepreneurs are quite high in the model. For microcredit, the simulations capture low take-up rates, borrowing and impacts that are concentrated in the higher end of the ability distribution, and small increases in entrepreneurship mostly due to the entry of marginal entrepreneurs. The baseline model somewhat overpredicts the increases in investment. However, with realistically higher interest rates on microloans, the model limits microcredit along the extensive and intensive margins and dampens the impacts of microcredit.

Several key lessons from the simulations involve the long run and general equilibrium implications, however. First, although microfinancial interventions can have substantial steady

\footnotetext{
${ }^{1}$ Business training interventions have not proven particularly effective, but the training in these programs involves technical training regarding livestock rearing.
} 
state and transitional impacts on development measures (income, consumption, productivity, etc.), no escape from aggregate poverty traps operating through wealth distributions and general equilibrium effects occurs in the simulations, since these traps do not exist. In this sense, we are unable to "make a miracle". Second, the simulations show that onetime redistribution in the form of asset grants alone tends to have only short run aggregate and distributional impacts, as eventually infused assets are depleted over time. In contrast, microfinance - at least subsidized low interest microfinance - has potentially longer run impacts because of its permanent availability and general equilibrium impact through wages. The cost effectiveness of smaller but sustained subsidies to microfinance vs. one-time asset grants is therefore of interest. It also suggests the importance of proper targeting and technical training for asset grant programs to have persistent effects. ${ }^{2}$

\section{Micro Empirical Estimates}

In this section, we review the evidence on asset grants to microentrepreneurs and the ultra poor, and on microcrediti nterventions. We then hypothesize about potential explanations for the patterns that emerge.

\subsection{Asset Grants to Microentrepreneurs}

Field experiments involving asset grants to microentrepreneurs have been undertaken in multiple countries: for example, Sri Lanka, Mexico, Ghana, and Nigeria. With one exception, all studies found significant profit increases from these asset grants. These findings are important experimental evidence for the long-held conjecture that at least some microentrepreneurs can generate above-market returns to capital, which in turn is evidence of the existence of financial constraints. We summarize these studies in Table 1.

The Sri Lanka study (de Mel et al., 2008) identified about 400 non-employer entrepreneurs in urban areas of Sri Lanka, and gave them small one-time grants either in kind (inventories or equipment) or in cash. They randomized between small and large grants equaling 460 or 920 PPP dollars, or roughly 3-6 months of average profits for these entrepreneurs. The impacts on investment were sizable: capital had increased by $70-130$ percent of the grant at 24 months (i.e., roughly the size of the grant), and monthly profits increased by 4-6 percent of the original grant. The implied monthly return on the grant was substantially above market interest rates, and would imply recovery of the original amount after 1.5-2 years,

\footnotetext{
${ }^{2}$ Kaboski and Townsend (2011) compares asset grants to village funds, and finds that the latter are more cost-effective overall. This model has indivisibilities but only an intensive investment margin, and is partial equilibrium.
} 


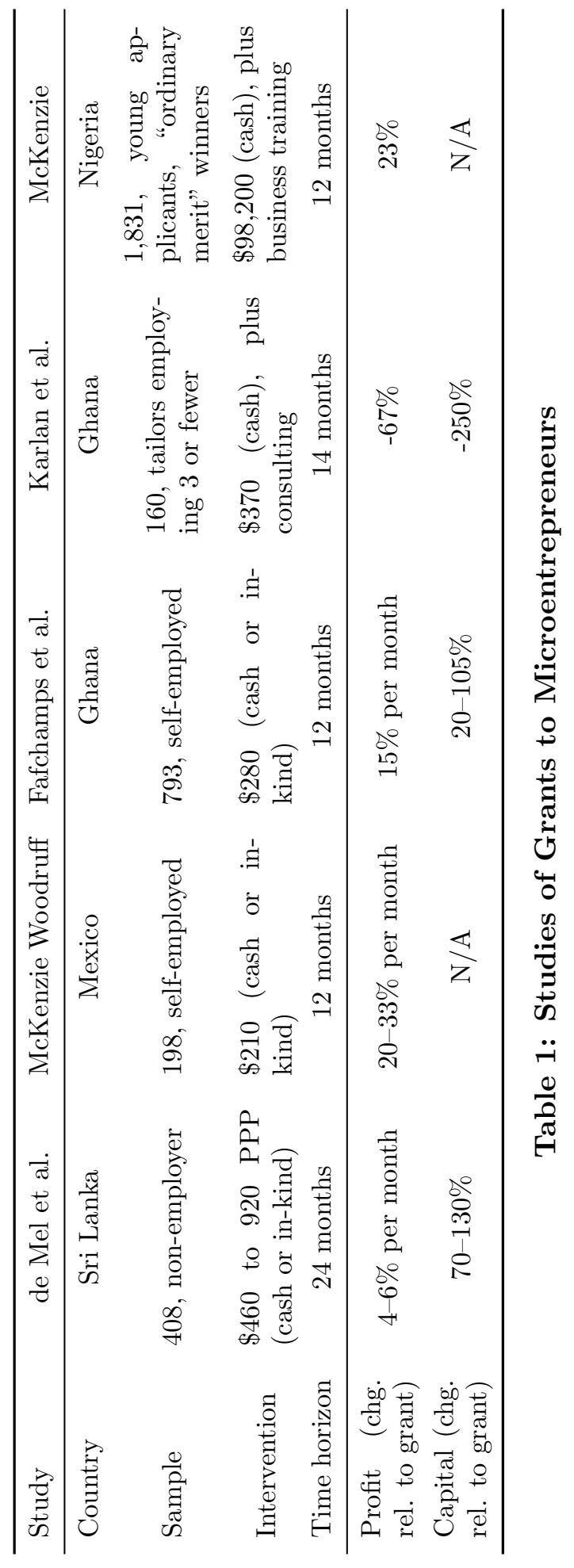


if it were a loan. Moreover, the timing of the growth could be characterized as immediate and stable. Indeed, the point estimates of the follow up work in de Mel et al. (2012) shows stability of higher profits even after 5 years, and the results are statistically significant. The sizable returns are evidence of potential financial frictions limiting profitable investments, but the fact that these impacts are stable over time, rather than leading to virtuous cycles of ever more reinvestment and growth indicate that the gains to relaxing these constraints may be limited. The Mexican study by McKenzie and Woodruff (2008) is a similar study lending further support to these findings. The study is smaller than the Sri Lankan study both in the sample size (about 200) and in the grant size (210 PPP dollars). They found extremely large returns to these small grants, between 20-33 percent per month at about one year, but acknowledged that sample attrition rate of 35 percent was potentially problematic.

Although returns may be high, the original Sri Lanka study also emphasized the strong heterogeneity in returns to capital, however. In particular, they found that the impacts were driven by those with disproportionally low levels of wealth, those with higher ability (measured by education attainment or through digit recall tests). Consistent with the wealth results, they found smaller returns on larger grants. Moreover, they were driven overwhelmingly by grants to men rather than to women. Fafchamps et al. (2013) further examine the impact on women. They granted about 280 PPP dollars to about 800 microentrepreneurs in Ghana and also found large impacts on monthly profits, which increased by about 15 percent of the original grant. These again imply high rates of return, but in contrast to the Sri Lankan study, they found that in-kind grants yielded larger impacts than cash grants. Moreover, the in-kind grants generated increases in profits among female entrepreneurs, which the Sri Lankan grants did not.

A study in Ghana provides a reminder that high returns to microentrepreneurs are not always and everywhere, however. Karlan et al. (2015) found that grants significantly decreased profits, as much as by 67 percent of the size of the initial grant. Their study experimented with a two-by-two intervention of grants and consulting, and neither intervention proved effective. They found some positive short run changes, which quickly reversed their course. A few ways in which this study differs from the Fafchamps et al. (2013) study should be noted, however. First, the sample size of 160 entrepreneurs was much smaller, about one-fifth of the size of the other study. Given the multiple branches of the sample, it may simply be that the control group was a statistical anomaly. Second, the grants were cash, while the impacts in the Fafchamps et al. (2013) were larger for in-kind grants. Third, this study focused on a particular occupation, tailors, and perhaps the industry differs from the typical microentrepreneur industry. Finally, their targeting rule allowed for slightly larger entrepreneurs with up to 3 employees. In practice, the differences were not large as their entrepreneurs 
averaged 0.35 employees and 0.86 apprentices. In addition, baseline profits were larger, so that their larger grants of 370 PPP dollars amounted to about 6 weeks of profit, comparable to the grant size in the other study.

Only one study has looked at the impacts of larger grants on larger firms. McKenzie (2016) examines the impacts of large grants, averaging nearly 100,000 PPP on young, aspiring entrepreneurs. The experiment stems from a Nigerian entrepreneurship competition, in which applicants submitted business plans and received business training, and the randomization was among a middle group of 1,200 applicants who were deemed of "ordinary merit" - a selected group of applicants but not the most promising. Profits increased by 23 percent, implying a monthly rate of return of 1-2 percent, somewhat lower than in other studies but comparable to market rates for SMEs in Nigeria. Thus, with more financial access, the control group should have been able to invest in principle.

In summary, the bulk of the evidence shows sizable returns to capital grants of modest sizes, equaling up to 6 months of profits on existing microentrepreneurs. On average, these grants lead to higher investment and profits, though the impacts are heterogeneous. The returns are somewhat lower for the wealthy, the less able, and female entrepreneurs.

\subsection{Asset Grants to the Ultra-Poor}

Microentrepreneurs are often not the poorest of the poor, those living on only a few PPP dollars per day. A natural question for poverty alleviation is whether asset grants could have substantial impacts on this population. Many of the ultra poor are involved in subsistence agriculture, where the microentrepreneur results are less relevant. On the one hand, the wealth results from the entrepreneur studies might make us expect high returns, but the results for low ability and female entrepreneurs suggest otherwise. In any case, a wide set of recent studies has given us strong evidence on the impact of asset grants to rural, ultra poor households with female heads. We summarize them in Table 2.

Several of the studies focus on a standardized program developed in Bangladesh by BRAC and exported to other countries. The studies focused on households headed by a female, and experimented with in-kind transfers of livestock, amounting to roughly 4-8 goats or 1-2 cattle/buffaloes. In PPP terms, the value of these assets are in the ballpark of the microentrepreneur grants described above, but they are somewhat larger and certainly larger as a fraction of the recipients' income. More important, the program is not a simple asset grant but is instead the lead part of a set of services offered to the participant households that together are designed as a micro-level "big push." These other services can include required or encouraged savings, technical assistance often in the area of livestock rearing, and a consumption supplement. One key purpose is to lower the chances that the household 


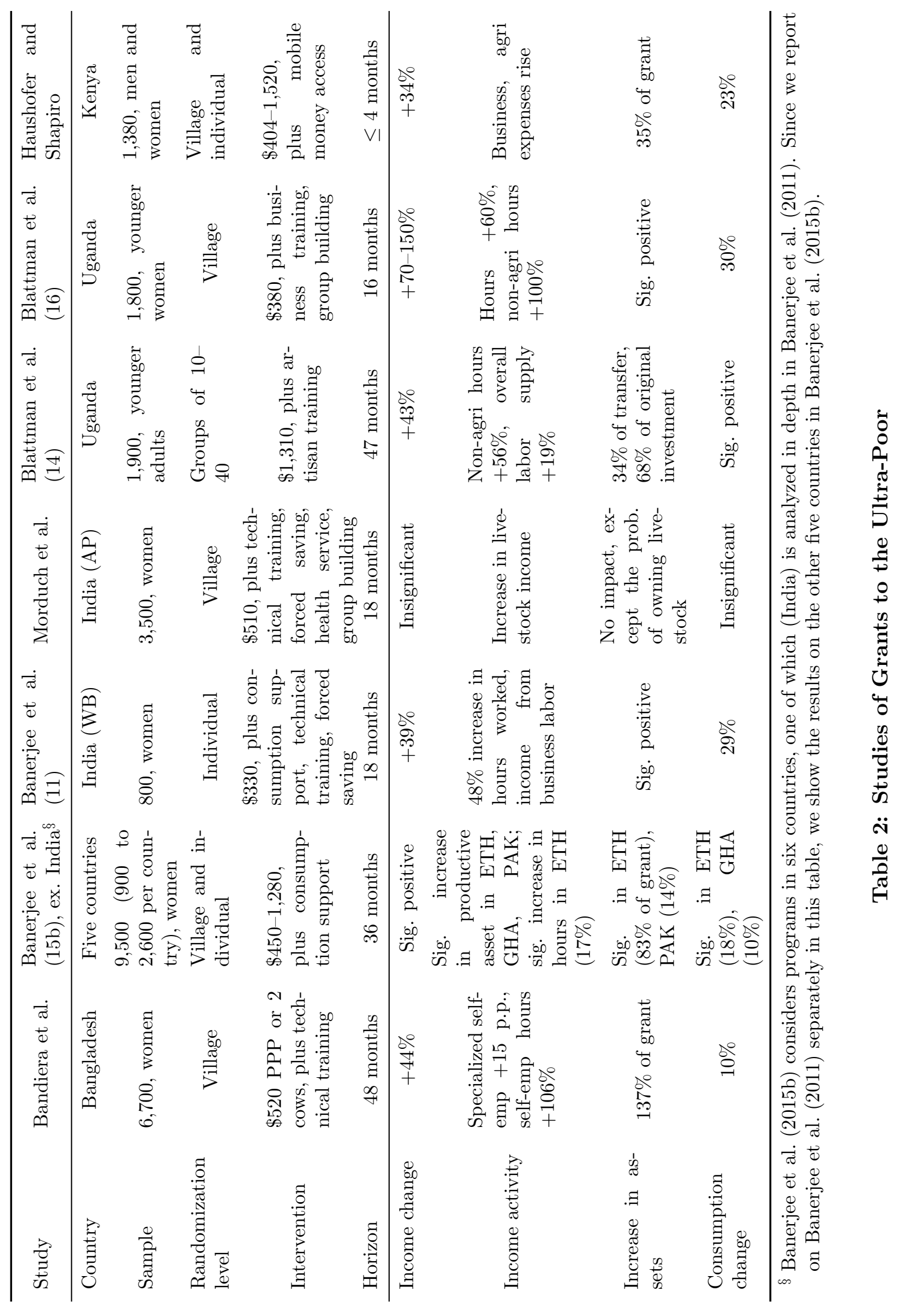


would need to liquidate the livestock assets for short-term needs.

Bandiera et al. (2016) evaluate the ultra poor program in the setting where it was developed, Bangladesh. ${ }^{3}$ Their results are the most impressive of these programs. Randomizing at the village level, they report experimental results up to 4 years after the livestock grants with a sample of 6,700 households. Four years out, the treatment has higher assets that exceed the original value of the asset grant by 40 percent. The fraction of women specializing in self-employment increased by 15 percentage points, and labor hours in self-employment doubled. Income is 44 percent higher as well. Putting this into perspective, this amounts to an extra income equivalent to 22 percent of the initial asset grant per month, comparable to the very high returns found with microentrepreneurs in Mexico. However, the program also involved technical assistance costs. ${ }^{4}$ Moreover, they find that consumption is 10 percent higher. Looking at the dynamics between 2 and 4 years, they find growth in assets, income, and consumption, but labor supply remains stable.

The largest and broadest study is Banerjee et al. (2015b) which presents experimental results for Ethiopia, Ghana, Honduras, Pakistan, Peru (and West Bengal, which we discuss below.) The samples in these countries range from 900 to 2,600, and over 10,000 households are involved in the analysis combined. They evaluate the impacts three years out, and find that assets are higher, but by less than the initial asset transfer. There is a great deal of variation across countries. Assets are significantly higher in Pakistan and Ethiopia, but the point estimates constitute 14 and 83 percent of the initial transfer, respectively. The study combines multiple measures into indices, which allows for more statistical power in terms of finding significant tendencies but makes it difficult to compare the magnitudes they report to other studies or theory. Nonetheless, they find statistically significant increases in their income index, in productive assets in Ethiopia, Ghana and Pakistan, and a significant 17 percent increase in hours in Ethiopia. They find significant increases of 18 percent in Ethiopia and 10 percent in Ghana.

The results in Banerjee et al. (2015b) are reported in more depth in Banerjee et al. (2011). In a sample of 800, where individual rather than village randomization was used, they find a substantial increase in assets, income, and consumption at 18 months. The measured increase in income of 39 percent amounts to a monthly return of 12 percent on the value of the asset. Here the cost of the program involves not only the grant and technical assistance, but also up to 9 months of food supplements (tantamount to per-capita consumption) and a saving requirement of 3 dollars per month. Nevertheless, the returns are sizable. Moreover,

\footnotetext{
${ }^{3}$ Emran et al. (2014) find very similar results for the BRAC program in Bangladesh based on earlier data but using non-experimental methods to account for selection bias.

${ }^{4}$ In conversations, the authors also reported the presence of food supplements and savings encouragement.
} 
the program led to an increase in consumption of 29 percent. Because measured consumption exceeds measured income, as is typical in survey data from developing countries, the absolute increase in consumption exceeds the increase in income. The consumption increase is thus financed not only by increased income generating activities but also by sales of assets.

A larger study in another Indian state (Andhra Pradesh) finds less promising results, however. In a sample of 3,500 households, Morduch et al. (2012) find no significant effects on income or consumption. They find increases in livestock and livestock income, but these are offset by lower levels of labor income. Like the Bengali program, this program incorporated technical assistance and mandatory savings, but it also differed in that it had a health component but no food supplement.

Looking across these studies, there is a pattern of sizable increases in income and consumption going together with increases in hours. In Bangladesh, West Bengal, and Ethiopia are the countries with the most promising results, and all showed increases in labor supply. In Andhra Pradesh, where jobs were widely available because of the presence of the National Rural Employment Guarantee Act (NREGA), there was no increase in income or consumption, but only movements from labor income to self-employed agricultural income. Bandiera et al. (2016) build a model where labor supply plays a key role, and it may be that such a model is only relevant in particular economic environments. Indeed, it is interesting to note that the two places with the largest observed gains, Bangladesh and West Bengal, have strong affinities, both cultural and socio-economic.

Other asset grant programs in east Africa exhibit positive yet relatively modest impacts. Blattman et al. (2014) examine transfers targeted toward young adults (aged 18-35) rather than women. The grants were cash, and sizable on average (1,310 PPP dollars), especially relative to the recipients' income. The grants were made at the group level, and in part they were used to finance artisanal training. Four years after the grant, the grantees had higher assets, with the difference being 34 percent of the original transfer or 68 percent of the original asset investment. Nonetheless, income was 43 percent higher, and this additional income constituted a monthly increase of about 5 percent, comparable to the returns to Sri Lankan entrepreneurs. The grantees had 19 percent higher labor supply on average, and 56 percent higher labor supply in non-agricultural/skilled labor activities.

As mentioned, the additional assets 4 years out are only a fraction of the original transfer. Indeed, the program had larger effects 2 years out. After 4 years, nearly half of the recipients no longer practice their trade. Although the program did not have a gender focus, the decline between years 2 and 4 is driven overwhelmingly by men. Nonetheless, the program is estimated to have a positive net present value.

Blattman et al. (2016) examine another program in Uganda, but this targets women 
in war torn areas of the country. The cash grants were considerably smaller (380 PPP dollars) and constituted just 17 percent of the total costs of the program, which included business skills training, follow up supervision, and group-building activities. The program was evaluated at 16 months, and the recipients had 60 percent higher labor supply and nearly twice as many hours in non-agriculture as those in the control, and their consumption was 30 percent higher. The increase in monthly income amounted to 7 percent of the initial transfer, again comparable to the Sri Lankan returns.

A final study is Haushofer and Shapiro (2013), which examines a program in Kenya offering grants averaging about 800 PPP dollars. The study had multiple levels of randomization including the size of total grants, the gender of recipients, and the timing of payments. Smaller grants were made over 9 months, while larger grants were made over 16 months. In principle, the drawn out payments might help households that struggle with inconsistent intertemporal preference unless a lump sum is needed for an indivisible, illiquid investment. The overall time horizon is much shorter, however, averaging about 4 months, which overlaps with the payment schedule. Over this short run, the program led to increases in income and consumption, but the monthly increase in income constitutes just 2 percent of the average total transfer, somewhat lower than the other studies. Using both a village and individual level design, they find no evidence of spillovers to nonparticipants, which is in harmony with the other studies.

In sum, the asset grant programs to poor rural, usually female-headed households lead to substantial increases in assets, income, and consumption. With the exception of the Bangladesh study, the initial increase in assets dissipates over time, however.

\subsection{Microcredit Evaluations}

The high apparent marginal returns on assets among portions of microentrepreneurs and the ultra poor suggest that financial frictions may be prohibitive for these groups, and could motivate microcredit as an alternative program for these populations that could potentially improve on asset grant programs in terms of both cost-effectiveness and identifying those with high returns. Indeed, this is the original, anecdote-based motivation for microcredit as a transformative financial intervention. A host of recent research has given a more nuanced and sober assessment of its impacts, however.

Banerjee et al. (2015c) report the results of six recent randomized evaluations of microcredit interventions in Bosnia-Herzegovina, Ethiopia, India, Mexico, Mongolia, and Morocco. These are summarized in Table $3 .^{5}$ In PPP terms, the average loans are of similar magnitudes

\footnotetext{
${ }^{5}$ Some of the information reported comes from the individual papers, while others come from the Banerjee et al. (2015c) overview article.
} 
to the asset grants, although somewhat larger. The studies tend to find: (i) relatively low take-up rates; (ii) increases in credit overall; (iii) increases in business activity, but (iv) little impact on overall measures of profits, income, or consumption. Together with these studies, Table 3 also includes two evaluations of village fund programs in China and Thailand, which show more positive results. There are some common findings, but also remarkable differences in both the programs and findings.

The first study (Attanasio et al., 2015) evaluates an expansion of microcredit within villages in Mongolia. Although generally Mongolia has a strong microcredit presence, the villages studied have relatively low baseline usage. The unique aspect of this study is the variation between joint liability and individual liability loans. The loans are relatively shortterm (6 months), and after 19 months they find that roughly half of those surveyed have taken up loans, which is higher than the other studies. The intervention increases the fraction with loans by 26 percentage points and the level of credit overall by 67 percent. They also find an 8 percentage point increase in the fraction of self-employed, and a 57 percent increase in labor supply. This is the lone study of traditional microcredit that finds any evidence of an increase in consumption, an 11 percent increase that seems to be driven by a significant increase in food consumption.

Crépon et al. (2015) and Tarozzi et al. (2015) study expansions of microcredit programs into rural areas, Morocco and Ethiopia, respectively. In Morocco, the program targeted those already involved in activities other than crops. Thus, it is unsurprising to not see an increase in the fraction of people involved in self-employment activities. After two years, the program still had low take up, with just 13 percentage points more having borrowed, but that led to a 64 percent increase in credit overall. Capital increased by 29 percent, and there was a decrease in labor supplied to non-self-employment activities. This yielded an increase in profits of 40 percent, which was marginally significant, but no significant impact on consumption.

The Tarozzi et al. (2015) study involves repeated cross-sections of households, but effectively panels of villages and "peasant associations", which are the unit of randomization. The microcredit program was joint with a family planning intervention that was ex post ineffectual. After three years, the fraction with loans was 25 percentage points higher in treatment villages, and credit had increased by 195 percent. Still, they found no impacts on businesses, capital, or profits, despite the program targeting potential entrepreneurs. The survey did not measure consumption.

Banerjee et al. (2015a) evaluate an urban expansion of microcredit in India, while Angelucci et al. (2015) combine both rural and urban expansions in Mexico. They find take up rates below 20 percent. Both programs find substantial increases in credit and its prevalence, 


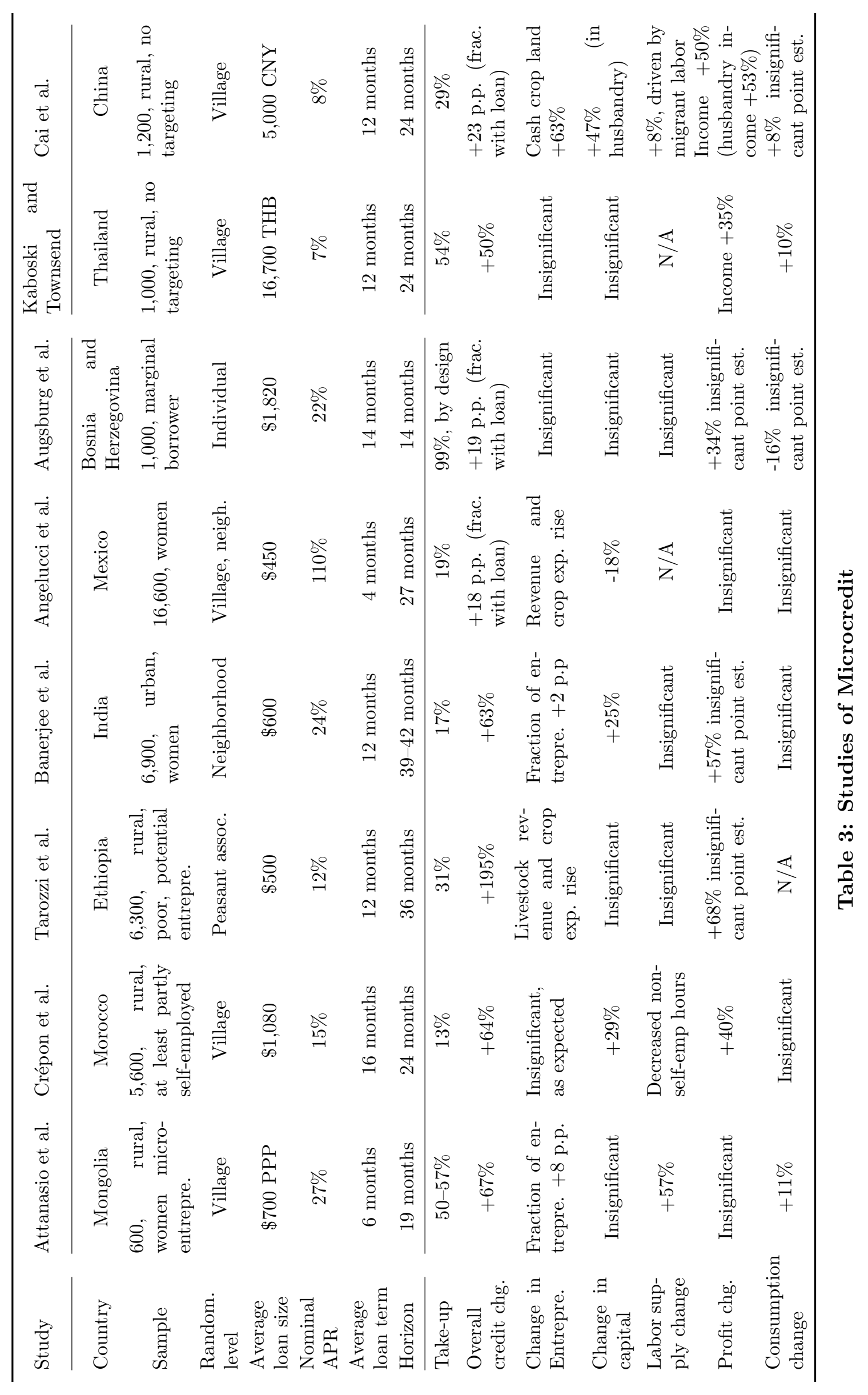


and different measures of business activity, but neither finds a significant effect on profits (although the point estimate for India is sizable) or consumption. India shows an increase in assets, while Mexico shows a substantial decline. The Mexico intervention is unique in that the loans were very short term (averaging 4 months).

The Bosnia-Herzegovina study (Augsburg et al., 2015) stands apart in several ways. First, it randomized at the individual level, targeting marginal borrowers who otherwise would not have qualified for loans. ${ }^{6}$ Second, the loan amounts were substantially higher, averaging 1,820 PPP dollars. By design, the take up rate approaches 100 percent. Still, they only find significant impacts on credit and nothing on entrepreneurship, profits, or consumption. Naturally, marginal borrowers make a unique sample, which may partially explain the none-result.

The two remaining studies examine village fund interventions and yield somewhat more positive results. Village funds differ in that they are largely independent of existing microfinance institutions and instead involve a transfer of funds to a village in order to set up its own quasi-formal institution. Kaboski and Townsend (2011, 2012) study introduction of village funds in Thailand. Although they lack a randomized control, the fact that the government gave the same amount of funds to all villages, regardless of their size, makes village sizes an effective instrument for the intensity of treatment. In the first two years, they find a near doubling of the level of short-term credit in the villages, a 35-percent increase in income, and a 10-percent increase in consumption. Followed over six years, the increase in credit is stable, but the increases in consumption and income are concentrated in the early years.

Cai et al. (2016) examine a similar village fund program in China, but had a randomized introduction at the village level. After two years, there is a 23 percentage point increase in the probability of having a loan, substantial increases in resources going to cash crops and animal husbandry, and a 50-percent increase in income per capita. Interestingly, total working days increase, but this is driven by migrant labor outside of the village (and province) rather than self-employed labor or labor within the village.

The setup of the Cai et al. (2016) study allows us to compare the results using the experimental variation with the results using quasi-experimental variation in village size of Kaboski and Townsend $(2011,2012)$. The results largely validate the village size approach, although the standard errors rise, highlighting the improved identification with field experiments.

A few other nuanced findings from the empirical work deserve discussion.

First, impacts tend to be heterogeneous. Kaboski and Townsend (2011) showed that households who are marginal for large indivisible investments benefited the most. Quantile

\footnotetext{
${ }^{6}$ Karlan and Zinman $(2010,2011)$ follow a similar approach.
} 
regressions in the special issue articles above show that impacts are often concentrated among the very highest percentiles. Banerjee et al. (2015a) provide further evidence that positive impacts are concentrated among existing entrepreneurs.

Second, Angelucci et al. (2015), Crépon et al. (2015), and Cai et al. (2016) examine impacts on (expected) non-participants, and find no spillovers. In contrast, Kaboski and Townsend (2012) find impacts of the Thai village fund intervention on local wages. Interacting the balance sheets of microfinance insititutions with government driven microfinance crisis and subsequent collapse of microfinance in Andhra Pradesh as a source of quasiexperimental variation, Breza and Kinnan (2016) find that day wages declined in areas where microcredit contracted more severely. Whether general equilibrium spillovers are important may depend greatly on the structure of the labor market and the relative importance of microfinance.

Third, the impact of the introduction of the program on the use of other credit products varies by study. Some find that the new intervention has no effect (Attanasio et al., 2015; Tarozzi et al., 2015), others find that it crowds out other sources (Augsburg et al., 2015; Banerjee et al., 2015a; Cai et al., 2016), while still others actually find crowding in (Kaboski and Townsend, 2011, 2012; Angelucci et al., 2015; Crépon et al., 2015; Greaney et al., 2016). Even at a more disaggregate level (e.g., bank loans, informal loans), the impacts vary from crowding out to crowding in.

Fourth, the long term impacts have been examined in two papers with different results. In Thailand, Kaboski and Townsend (2011) find that impacts fluctuate over six years, but are concentrated in the early years. Banerjee et al. (2014) find fluctuations in treatment effects over time but also finds some contrasting results, at least for existing entrepreneurs. They examine the impact of the collapse of microcredit in Andhra Pradesh again, looking at whether the benefits persist even after microcredit has exogenously declined. They find that existing entrepreneurs are more profitable six years later, but the more reluctant entrepreneurs' profitability has declined.

Finally, impacts tend to vary substantially based on program details. ${ }^{7}$ Attanasio et al. (2015) found that only joint liability loans led to positive impacts. Although Field and Pande (2008) found no impact of moving from weekly to biweekly payment frequency, Field et al. (2013) shows that a two month delay before the onset of required repayment leads to higher levels of entrepreneurial investments. Finally, Greaney et al. (2016) show that the contractual structure of the administrative agents in self-help groups impacts both entrepreneurial activities and group membership.

\footnotetext{
${ }^{7}$ Kaboski and Townsend (2005) is an early paper showing the importance of program policies for impacts in a non-experimental setting.
} 


\subsection{Taking Stock across Interventions}

The evaluations uncover some commonalities but also strong differences across the interventions.

Among the commonalities, one important theme is that of individual heterogeneity. The entrepreneur grants focused on the dimensions of initial assets, ability, and gender. In many countries, the ultra-poor programs showed broad-based impacts (Banerjee et al., 2015b), but even they exhibit a factor of 20 difference in the impacts on income between the 90th and the 10th percentiles. Moreover, while those specializing in wage labor shifted activities toward self-employment, the impacts on earnings were much larger for those already specialized in self-employment (Bandiera et al., 2016). The microcredit work highlighted the low take-up, and the concentration of largest impacts near the very top of the distribution.

A second, related generalization is that even among existing entrepreneurs, interventions can increase profitability, indicating constraints along the intensive margin. The intensivemargin impacts of the entrepreneur grants are obvious, but we also find impacts of microcredit and ultra-poor grants among the existing self-employed. On the other hand, the ultra-poor grants also show impacts along the extensive margin of entrepreneurship, perhaps only for the severely constrained, however.

A third common finding was a general lack of sustained growth patterns, at least among the bulk of the population. Among those studies with multiple endlines, impacts were generally realized fairly rapidly, and either remained steady or fell over time. Across the ultra-poor programs, the additional assets at endline were generally smaller than the initial grants. The one exception is the Bangladesh ultra-poor program, which led to increases in assets, income, and consumption even between years 2 and 4 .

The key difference across the interventions is the smaller impact of microcredit on income and consumption relative to the grants to entrepreneurs (which impacted profits positively) and and to the ultra-poor. We hypothesize several possible reasons for this difference, along with some supportive evidence.

The most obvious explanation is that the burden of repayment limits the impact of microcredit relative to grants. Take-up tends to be low, and so - in the absence of strong spillovers - much of the population is simply not affected. The need to repay could also lower the impact on consumption, even among those who borrow. However, we also see small impacts on income, indicating that this is unlikely to be the only factor. Repayment can impact the income generating investments themselves. First, by definition, relatively high interest rates make investments less profitable. Second, the need to make immediate repayments may limit investments with longer horizons, even if they are otherwise profitable.

In considering the burden of repayment, the village fund programs in China and Thailand 
are of particular interest, since they fall somewhere in between grants and pure microfinance. The fund itself is a grant to the village, but it is channeled to the villagers in the form of loans that need to be repaid. They had lower interest rates ( 8 and 7 percent, respectively) and longer payment schedules (a single repayment at the end of the loan). They showed relatively high take-up (54 and 29 percent, respectively) and resulted in strong increases in income (in both) and consumption (significant in Thailand). In addition, the microcredit study in Morocco allowed for a 2-month grace period for animal husbandry investments, and it was the only pure microcredit study to find any evidence of higher profits. This is again consistent with Field et al. (2013), which documents the impact of a 2-month grace period in India.

Another explanation is the difference in the targeted population of microcredit relative to the grant programs. The programs to the poor show that grants can have large impacts on very poor populations (at least in the short run), and the entrepreneurship grants also found larger impacts on those with fewer assets. Microfinance programs, however, often do not lend to the poorest populations. Related, microcredit may be a "small" intervention in the sense that, in many places, those with the most to gain by borrowing may already have access to other forms of credit, and so the interventions are only changing the terms. Those whose investments respond to small changes in terms are likely those with the most marginal returns. This would be a good description of those areas in which significant crowding out was observed.

Another difference is that microcredit programs have often targeted women, and with cash. The entrepreneurship grants found that it was difficult to increase the profitability of women entrepreneurs, at least with cash. They also found that more educated entrepreneurs exhibited bigger impacts, but women tend to be less educated than men in many developing countries. Here the village fund programs are again an interesting comparison, since they did not target women specifically and the gender education gap is small in both China and Thailand.

\section{Taking Stock of Theory}

We now turn to evaluating our understanding of these empirical patterns through the lens of quantitative theory. We present the basic model as developed in a series of papers: Buera and Shin (2013) and Buera et al. (2011, 2012, 2014). It captures many common elements in the theoretical and quantitative literature and financial frictions have quantitative bite both in the steady state (Buera et al., 2011) and transitionally (Buera and Shin, 2013) for a more comprehensive review of this literature see Buera et al. (2015). We evaluate 
the theory a priori based on its consistency with many of the common patterns above, discuss its implications on poverty traps, and then assess its ability to predict the variety of interventions.

\subsection{Basic Model}

Consistent with the commonalities discussed above, the quantitative theory has focused on models with (i) extensive entrepreneurship decisions, (ii) intensive investments, (iii) individual heterogeneity in wealth, productivity/ability, and whether or not their entrepreneurship is simply a matter of necessity, and (iv) forward-looking decisions regarding entrepreneurship, investment, and saving. We reproduce this basic model below.

Individuals differ in terms of their productivity as workers $x$ and entrepreneurs $z$. As entrepreneurs, they produce output using capital $k$, labor $l$, and a diminishing returns to scale production function $z k^{\alpha} l^{\theta}$. Worker productivity and entrepreneurial productivity follow Markov processes that are independent of each other. Specifically, with probability $\gamma$, the value of the entrepreneurial productivity remains constant from one period to the next, $z^{\prime}=z$, and, with probability $1-\gamma$, it is a random draw from a Pareto distribution, $z^{\prime}=\zeta \sim-\eta \zeta^{-\eta-1}$. A worker's productivity or efficiency units of labor is assumed to follow a two-state symmetric Markov chain, $x \in\left\{x_{l}, x_{h}\right\}$, with $x_{l}<x_{h}$. The probability of the shocks remaining in its current value is $\pi$ and $\mathbb{E}[x]$ is normalized to one.

The financial frictions in the model follow a simple yet useful form and stem from limited enforceability of contracts. In particular, by defaulting on their credit contracts, entrepreneurs can keep a fraction $1-\phi$ of the period's output net of labor costs and the same fraction of the undepreciated capital. Defaulting individuals regain access to credit markets in the following period, and hence the limited commitment constraint has a simple static representation.

Given the interest rate $r$ and the wage per efficiency units of labor at time $t, w_{t}$, the problem of an individual with wealth $a$ and worker/entrepreneurial productivity $x$ and $z$ at time $t$ is recursively formulated as:

$$
\begin{aligned}
& v_{t}(a, x, z)=\max _{c, a^{\prime}, k, l \geq 0, e \in\{0,1\}}\left\{\frac{c^{1-\sigma}}{1-\sigma}+\beta \mathbb{E}_{x^{\prime}, z^{\prime}}\left[v_{t+1}\left(a^{\prime}, x^{\prime}, z^{\prime}\right) \mid x, z\right]\right\} \\
& \text { s.t. } \quad c+a^{\prime}+T_{t}(a)-S_{t}(a) \leq e\left[z k^{\alpha} l^{\theta}-(r+\delta) k-w_{t} l\right]+(1-e) x w_{t}+(1+r) a \\
& \text { and } \quad z k^{\alpha} l^{\theta}-w_{t} l-(r+\delta) k+(1+r) a \geq(1-\phi)\left[z k^{\alpha} l^{\theta}-w_{t} l+(1-\delta) k\right] \text { when } e=1
\end{aligned}
$$

where $c$ is consumption and $e$ is the discrete occupational choice $(e=1$ for entrepreneur and $e=0$ for wage worker). The second inequality captures the financial friction for an entrepreneurs, which places an upper bound on available capital. Buera et al. (2012) shows 
this reduces to $k \leq \bar{k}(a, z ; \phi)$, where $\bar{k}$ is increasing in wealth $a$, ability $z$, and $\phi$. In our modeling of financial frictions, $\phi$ is the unique parameter indexing the enforceability of contracts across countries, and so it captures financial development and the availability of credit. ${ }^{8}$ As $\phi$ varies from zero to one, the model spans the spectrum of cases from financial autarky to perfect credit markets.

The basic components of the model can be calibrated quantitatively to key measurables, including the firm size distribution (which identifies thick-tailed ability distributions), the income distribution (which, given the thick tails, identifies the return to scale parameters), and larger firms' exit rates (which identify the frequency of shocks to productivity). The parameters of the labor income process can be calibrated to the autocorrelation and standard deviation of income in rural areas of developing countries, which reflect the dearth of labor market opportunities. Given the distribution of heterogeneous productivities in the population, this model can be aggregated to solve for endogenous levels of financial intermediation, productivity, aggregate capital, etc. One can do this within the framework of a partial equilibrium model (where wages and interest rates are taken as given), a small open economy (where the wage is endogenous but the interest rate is given), or a fully general equilibrium. Both steady-state and transitional analyses are computationally tractable.

A few words on some implicit modeling assumptions vis-a-vis real world empirics. First, we follow the quantitative literature in fixing total labor supply (hours worked in business or the labor market) exogenously. Although labor supply was often impacted in the experimental work cited above, this is a reasonable benchmark for looking across programs because the sign of impacts varied across studies. Nonetheless, labor supply seemed to play an important role in the more successful ultra-poor grants to women. Second, occupational choice is binary. Empirically, we often observe households and even individuals whose income and hours are attributed to both labor and business/self-employment. Nonetheless, we view this as preferable to ignoring the natural indivisibility that comes from minimum efficient scale or fixed costs. Buera et al. (2011) models these fixed costs explicitly and emphasizes how they vary across sectors, and Buera et al. (2014) argue that such a fixed cost may be necessary to explain the persistent effects on the right tail of the wealth distribution from the land distribution in Bleakley and Ferrie (2013). Similarly, Banerjee et al. (2014) argues that their microfinance results are consistent with a model with fixed costs and technology choice within industries. ${ }^{9}$

One can easily consider the decisions of a single individual taking prices as given, or a full

\footnotetext{
${ }^{8}$ Buera et al. (2015) reviews alternatives to this form in the literature.

${ }^{9}$ Kaboski et al. (2014) develops an explicit quantitative model with this technology/scale choice and assesses the relative role for cash-denominated vs. in-kind microfinance.
} 
general equilibrium. One can consider either a stationary equilibrium where aggregates and prices are stable or a dynamic equilibrium where these aggregates and prices transition over time. The model therefore holds a theory for both household and aggregate behavior, and the latter allows us to have insight into potential impacts of both scaled up micro-interventions and macro policies.

\subsection{Financial Frictions and Poverty Traps}

When considering the role of poverty traps in the model, it is important to distinguish between individual and aggregate poverty traps. Within the model, we define poverty traps as self-reinforcing differences in steady-state income that result from differences in initial wealth conditions. Without financial frictions, agents with identical productivities would have identical occupational and productive choices regardless of their wealth. Since all individual decisions coincide, aggregate productive behavior (and ultimately aggregate savings behavior) is unaffected by the distribution of wealth.

However, when financial frictions are present, the model can lead to individual-level poverty traps in which agents with identical productivities but different initial wealth levels behave differently and their wealth levels diverge. Buera (2008) and later Banerjee and Moll (2010) show the importance of self-financing in driving these poverty traps. Initial wealth determines how quickly saving to self-finance would pay off, and agents with low initial wealth do not find it optimal to save for so long. At the macro level, financial frictions lower the demand for capital, while self-financing motives increase the supply. Both of these in turn lower equilibrium interest rates, leading those with no intention of becoming entrepreneurs to dissave instead.

We visually demonstrate this in Figure 1. The dashed lines illustrate the occupational choice decision as a function of individual wealth and productivity. Under financial frictions it is not only high productivity that leads people to become entrepreneurs but also high wealth. The solid lines represent the thresholds above which agents save and below which they dis-save. For agents with high productivity, the wealthiest agents save while the poorest agents dis-save. The intersection of the occupational choice and poverty trap lines indicate that there are workers who are saving to eventually escape poverty, while there are rich entrepreneurs who are eventually converging to poverty. Of course, shocks to ability can alter these dynamics, so that these "poverty traps" are not absorbing states in the long run.

Beyond individual level poverty traps, however, many stylized theories of entrepreneurial choice predict the possibility that financial frictions can lead to poverty traps for entire economies by distorting entrepreneurship, e.g., Banerjee and Newman (1993), Ghatak and 


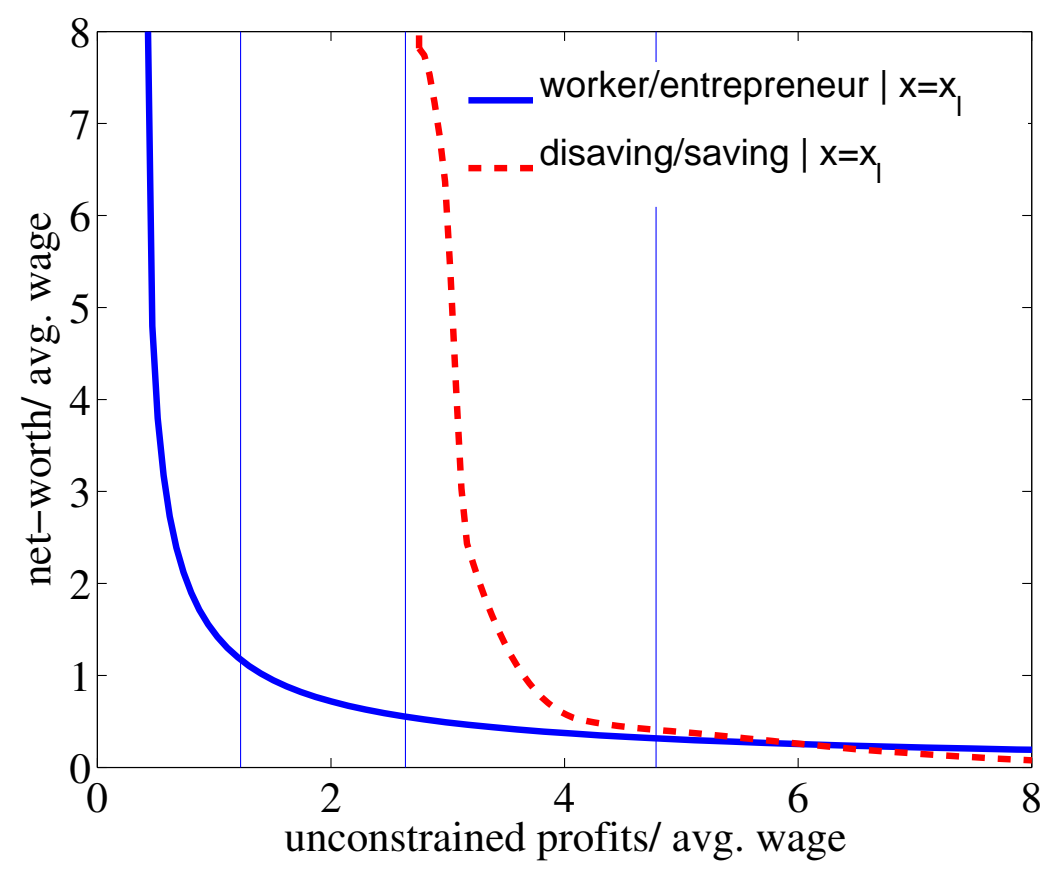

Fig. 1: Occupation and Saving Decision Map

Jiang (2002), Aghion and Bolton (1997) and Piketty (1997). ${ }^{10}$ Poverty traps arise in these models because initial distributions affect general equilibrium wages or interest rates, and in turn aggregate dynamics. If few people have the required initial assets to become entrepreneurs, wages and interest rates will be low, which leads to a persistence of a wealth distribution in which few have the resources to become entrepreneurs. The models typically assume a small role for forward-looking self-financing motives and intensive margins in the scale of establishments that to the low cost of labor and capital. For example, Banerjee and Newman (1993) and Ghatak and Jiang (2002) lack an intensive margin in the demand for labor that would make the equilibrium wage respond continuously rather than discretely. Piketty (1997) lacks any labor market and, like Aghion and Bolton (1997), also abstracts from an intensive margin for capital that could respond to the interest rate. Moreover, all of these models have warm-glow savings behavior.

Qualitatively, the mechanisms emphasized in the poverty trap literature (lower interest rates and wages due to constrained entrepreneurial borrowing) are present in our benchmark model, and indeed with the self-financing motive, the impact on interest rates can be exacerbated. The benchmark model also contains non-convexities in production, which could generate multiple equilibria. Nevertheless, quantitative versions of these models, when prop-

\footnotetext{
${ }^{10}$ Matsuyama (2011) provides an excellent recent review of these and related results.
} 
erly mapped to the data, do not lead to aggregate poverty traps - e.g., Giné and Townsend (2004) and Buera et al. (2011) - but only slower convergence to a unique stationary distribution, the main point of Buera and Shin (2013). ${ }^{11}$ As explained in Buera et al. (2014), aggregate poverty traps disappear once one relaxes the above mentioned simplifying assumptions needed for analytical tractability. In addition to the intensive margins, the productivity shocks assure churning in the distribution of wealth and ability that leads to uniqueness.

\subsection{Assessing Poverty Interventions}

Variants of the above model have been simulated to assess asset grants (Buera et al., 2014) and microcredit (Buera et al., 2012). In these papers, short run partial equilibrium simulations are compared to some of the above empirical results, and the longer run, general equilibrium, and macroeconomic implications of the scaling up of these programs are assessed. We review these results before extending them to evaluate the role of high lending rates on the impacts of microcredit.

\subsubsection{Returns to capital among entrepreneurs}

Before using the quantitative model to assess the aggregate and distributional impacts of poverty interventions, we first illustrate the distribution of the marginal product of capital in the model economy. These returns provide a natural benchmark to compare with the estimates of the return to capital from the asset grants to micro-entrepreneurs in Section 2.1. The micro-estimates on the return to capital provide a natural test of the quantitative theory.

In Figure 2 we present the marginal product of capital among entrepreneurs. In the top panel, we show the average marginal product of capital among entrepreneurs in a given wealth percentile. For entrepreneurs in the bottom 10 percentiles, the (annual) return to capital net of depreciation is between 25 and 75 percent. The measured returns to capital to large interventions in the Nigeria study (McKenzie, 2016) are close to the lower end of this range, while the returns in the Sri Lanka study (de Mel et al., 2008) are slightly above the upper end of this range. The large returns found in the Mexico study (McKenzie and Woodruff, 2008) or the Ghana study (Fafchamps et al., 2013) are only rationalized if they are interpreted as capturing an average return to capital for entrepreneurs in the lowest percentile of the asset distribution. In the bottom panel, we plot the average marginal product of capital among entrepreneurs with a given establishment size, measured by the number of entrepreneurs. Since with few exceptions, the real world programs relate to the

\footnotetext{
${ }^{11}$ See also Moll (2014) for a theoretical analysis of this point.
} 

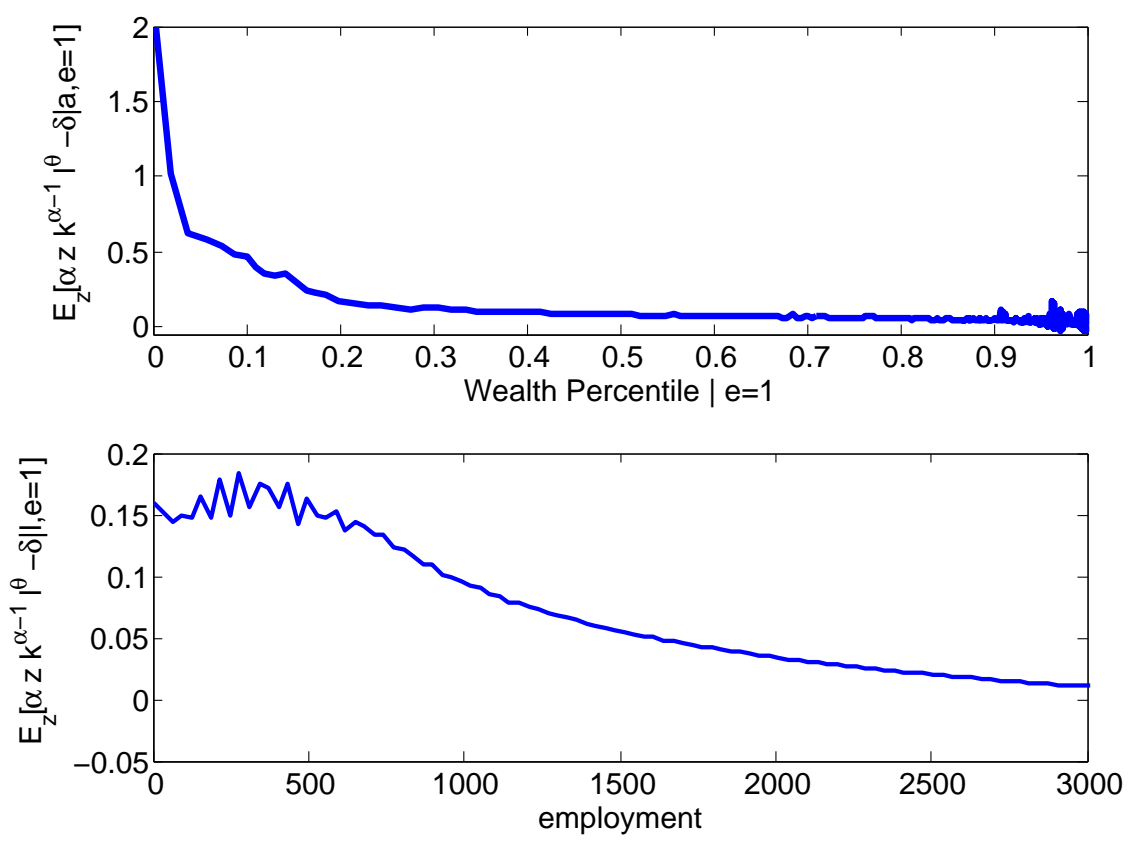

Fig. 2: Average Marginal Product of Capital, by Entrepreneurial Wealth and Size (Employment)

self-employed without employees, the relevant group in the model is non-employers in the far right end, whose average annual return exceeds 15 percent. Overall, this figure shows that the return to capital is very heterogenous among entrepreneurs in the calibrated model.

\subsubsection{Asset grant programs}

Buera et al. (2014) assesses the role of asset grant programs in the context of a small open economy with fixed interest rate. ${ }^{12}$ In particular, the transitional dynamics following an unexpected redistribution of wealth from the wealthiest toward the poorest are analyzed. The redistribution establishes at that point in time a minimum wealth in the economy equal to double the average annual wage in the initial stationary equilibrium, and is funded in an extreme fashion by instituting a one-time, 100 percent tax on wealth above a particular threshold, $\bar{a} .{ }^{13}$ The size of the redistribution is fairly comparable to the asset grants to the poor summarized in Table 2, which is estimated to range from about 5 months of income to 3 years of income. ${ }^{14}$ The cash grants to entrepreneurs in Table 1 are a bit smaller in

\footnotetext{
${ }^{12}$ In order to capture the poor saving opportunities in developing countries, we set this interest rate to zero, which is two percent lower than the historical average in developed economies.

${ }^{13}$ Specifically, we implement in the initial period the wealth grant $S_{0}(a)=\max \{2 w \mathbb{E}[x]-a, 0\}$, which is financed by a one-time tax over the wealthiest individuals, $T_{0}(a)=\max \{a-\bar{a}, 0\}$, where $\bar{a}$ is chosen to satisfy the static government budget constraint.

${ }^{14}$ These calculations are complicated because income may be understimated (e.g., people underreport noncash income or income of other household members), and also because many studies report household
} 
absolute terms, but much smaller as a fraction of reported income of the entrepreneurs $(0.5$ to 6 months of baseline profits). The exercise in Buera et al. (2014) is less comparable to the entrepreneurial grants, however, since they target the poor rather than small scale entrepreneurs.

In medium run projections of Buera et al. (2014), the impacts dissipate over time but largely remain after 4 years, but they are substantially smaller than those found in the empirical study. The program matches the empirics in that the fraction of people that pass over the poverty trap thresholds illustrated in Figure 1 is relatively small. Initially, 17 percent of the treated population switches to entrepreneurship. This compares well with the 15 percentage point increase in Bandiera et al. (2016). In terms of labor hours, it constitutes a roughly 200 percent increase in hours to entrepreneurship for this population, which is greater than the results in Table 2 that vary between 50 and 110 percent. In this sense, the strict occupational choice may lead to too strong a result with hours.

Qualitatively, the model also predicts an increase in earnings, but quantitatively the effects on earnings are just 4 percent. This is in line with the negligible impact on income reported in Morduch et al. (2012) but substantially smaller than the promising results found in the other studies in Table 2. Recall that where increases in income and consumption were substantial, they were accompanied by increases in labor supply, and the labor-leisure decision is not considered in the model. Alternatively, perhaps we can interpret these increases in income as resulting from an increase in productivity $z$ as a result of the technical training, which is not in the benchmark model. Thus, the large and sustained increase in earnings that some of the empirical work reports is not really a puzzle for theory.

The model matches most of the studies, with the exception of Bandiera et al. (2016), in having the impacts fall over time, however. After 4 years, the entrepreneurship rate is just 8 percentage points higher, and earnings are just 3 percent higher. Again, in line with the empirics, the impacts in the model are very heterogeneous across individuals, with the earnings of the treated individuals in the 90th (95th) percentile of the entrepreneurial productivity increasing by 11 (15) percent in the second year. Thus, the model has potential to have somewhat larger impacts for marginal entrepreneurs, but not the large gains reported in Table 1. In any case, the model is certainly consistent with a lack of a virtuous cycle of growth for the average recipient.

Although the model cannot match the magnitude of the observed income increase, the long run macroeconomic impacts reported in Buera et al. (2014) are still of interest. These aggregate effects include those on both the recipients, non-recipients, and those taxed by the redistribution. The wealth grants have a positive effect on aggregate total factor productivity income, which we need to convert into income per working age household member. 
(TFP) but a relatively larger negative impact on aggregate capital. The increase in TFP is due to the net entry of productive entrepreneurs and the capitalization of poor entrepreneurs with relatively high marginal products of capital. On impact, the decline in capital arises for the following reasons. The funds for the wealth grants come from rich active entrepreneurs who decrease their capital input by more than the drop in their wealth, since the acquisition of capital is based on leveraging wealth as collateral. This decrease is not completely offset by the grant recipients, because not all of them choose to become active entrepreneurs. In a small open economy, the redistribution of wealth therefore leads to a drop in the capital used in production and a capital outflow.

The net effect of the increase in productivity but decrease in capital on aggregate percapita income is negative but small. Although these mechanisms may be offset by the larger gains in income experienced by recipients in the empirical work, the capital decline mechanism in the model may still be an important consideration at the macro level.

All of these impacts, however, are transitional. Since the overall distribution of ability remains constant, wealth levels gradually return to their stationary distribution. There is no aggregate poverty trap to begin with, and so in the long run, the one-time wealth redistribution can cause no aggregate escape, and the economy returns to their original state.

\subsubsection{Microcredit programs}

Buera et al. (2012) reports parallel results for the impacts of microfinance. They model microcredit as a new alternative intermediation technology that allows anyone access to a small level of credit for capital, $b^{M F}$, regardless of wealth or ability. The financial constraint on capital is thus relaxed to:

$$
k \leq \max \left\{\bar{k}(a, z ; \phi), a+b^{M F}\right\}
$$

where the second element of the maximum captures the microcredit option. They run alternative models, but we report the results without the labor shock as it provides the simplest benchmark. ${ }^{15}$

Their benchmark analysis sets $b^{M F}$ at $150 \%$ of annual wages, which implies a maximum microloan size relative to per-capita expenditures of one and an average microloan size relative to per capita expenditures of 0.1 . This average is comparable to the levels of average loan size to income of 6-43\% reported by Banerjee et al. (2015c) in all but one of the empirical

\footnotetext{
${ }^{15}$ In an extension they consider a stark calibration of a labor shock where $x_{l}=0$ to capture an individual who is forced into entrepreneurship because he has no labor market option. They choose the process of the labor shock to match the high rates of entrepreneurship that are typical in developing countries.
} 
evaluations in the special issue. In the aggregate, it leads to total microcredit constituting 30 percent of overall credit, somewhat smaller than the 33 percent in Thailand (Kaboski and Townsend, 2011, 2012) or the 44 percent in India (Banerjee et al., 2015c).

The model does well in generating small take-up rates, 11 percent in the population overall, somewhat lower than the empirical estimates in Table 3, but those microcredit programs targeted marginal populations. The model also does well in predicting heterogeneous impacts, where both take up and impacts are concentrated in the top decile of the entrepreneurial ability distribution.

In the short run, partial equilibrium (i.e., small scale) simulations, the model predicts significant impacts on entrepreneurship (an increase of 4 percentage point) overall and investment by borrowers (a 46 percent increase), but small effects on overall consumption (a 1 percent increase). The increase in entrepreneurship is on the high end of the empirical studies, which ranges from no impact in several countries to 2 and 8 percentage points in Indian and Mongolia, and the increase in investment is also larger than in most. The Chinese study shows a $48 \%$ increase in investment, however, which is comparable to the simulation. The small increase in consumption is in line with the majority of the studies. Thailand and Mongolia show significant increases of roughly 10 percent, while the others exhibit negligible increases. In sum, the model does well in predicting the impact on entrepreneurship and consumption, but somewhat overpredicts the impact on investment. ${ }^{16}$

The aggregate impacts of microcredit are similar to those of the asset grants in the model. Capital decreases as income and resources are redistributed toward the poor who have lower saving rates. The impacts on TFP is positive, but on net, the impacts of microcredit on per-capita income are small. ${ }^{17}$

The main long run impact of microcredit is that it is highly redistributive. Indeed, in contrast to the one-time asset grants, the permanent availability of the microcredit option to poor households has long run impacts. Despite low take up, the option to finance entrepreneurship leads to a general equilibrium increase in the wage level, which is consistent with the findings of Kaboski and Townsend (2012) and Breza and Kinnan (2016). When widely available, microcredit can therefore be highly redistributive, even if the take-up rates are low. Of course, these impacts are within a model where microcredit has substantial impacts on entrepreneurship and investment.

\footnotetext{
${ }^{16}$ In the version of the model in which a sizable fraction of the population faces a lack of labor market opportunities and therefore become necessity entrepreneurs, microcredit has a bigger impact on consumption (a 20 percent increase).

${ }^{17}$ In the case with necessity entrepreneurs, the effects on per-capita income can be even negative, although consumption increases.
} 


\begin{tabular}{|c|c|c|c|c|c|c|}
\hline \multirow[b]{2}{*}{ MF Lending rate } & \multicolumn{3}{|c|}{ Short Run PE } & \multicolumn{3}{|c|}{ Long Run GE } \\
\hline & $-4 \%$ & $6 \%$ & $36 \%$ & $-4 \%$ & $6 \%$ & $36 \%$ \\
\hline Wage & & by definitiol & & 1.05 & 1.04 & 1.01 \\
\hline Output & 1.07 & 1.04 & 1.02 & 1.02 & 1.02 & 1.01 \\
\hline Capital & 1.03 & 1.01 & 1.01 & 0.94 & 0.96 & 1.00 \\
\hline TFP & 1.00 & 1.03 & 1.02 & 1.04 & 1.03 & 1.01 \\
\hline Consumption & 1.01 & 1.01 & 1.01 & 1.03 & 1.03 & 1.00 \\
\hline Avg. $z$ (active entrepre.) & 1.01 & 1.02 & 1.01 & 1.03 & 1.04 & 1.02 \\
\hline Fraction of entrep. ${ }^{\S}$ & +0.04 p.p. & +0.01 p.p & +0.00 p.p & +0.03 p.p & +0.02 p.p & +0.00 p.p \\
\hline
\end{tabular}

$\S$ Deviations from the no-microcredit economy. All other quantities are divided by their respective values in the no-microcredit economy.

\section{Table 4: Simulation with Different Interest Rates on Microloans}

\subsection{New Analysis with Interest Rate Spreads}

In Section 2.4, we conjectured that the interest rate charged on microloans may contribute to the varying impacts both within microfinance interventions, and across microcredit and the asset grant interventions. We pursue this formally here within the context of our model. In the model results of Section 3.3.3, the interest rate on microcredit was the same as the the low rate available to savers and borrowers from formal finance. Here we add microcredit-specific intermediation costs that lead to higher interest rates on microfinance loans. In principle, the variation in these spreads may reflect different rates of subsidies toward microfinance. We simulate each lending rate as its own unique scenario.

In the simulations below, the interest rate on savings is -0.04 . Table 4 reports results for interest rates charged on microcredit of $-0.04,0.06$ (comparable to the low interest village funds in Table 3) and 0.36 (toward the higher end of the interest rates reported in Table 3), where all quantities are normalized by the respective levels in the no-microcredit economy. Focusing on the short-run, partial equilibrium results in the first three columns, we see that the interest rates matter considerably. At market interest rates, in the short run, the model predicts a 3 percentage point increase in the fraction of entrepreneurs in the population, a 3 percent increase in capital, and 7 percent increase in output. At the intermediate interest rates, comparable to the village funds, these impacts are smaller, but there is still a 4 percent increase in output, and a 1 percentage point increase in the fraction of entrepreneurs. At the high interest rates, the impact on output is just 2 percent and there is no impact on entrepreneurship. In the short-run, the increase in consumption - in this model without necessity entrepreneurs - is small across the board, just 1 percent, however.

Focusing on the long run, GE impacts, we see the patterns discussed above for the low and moderate interest rates: increases in the wage, reductions in capital accumulation, and 

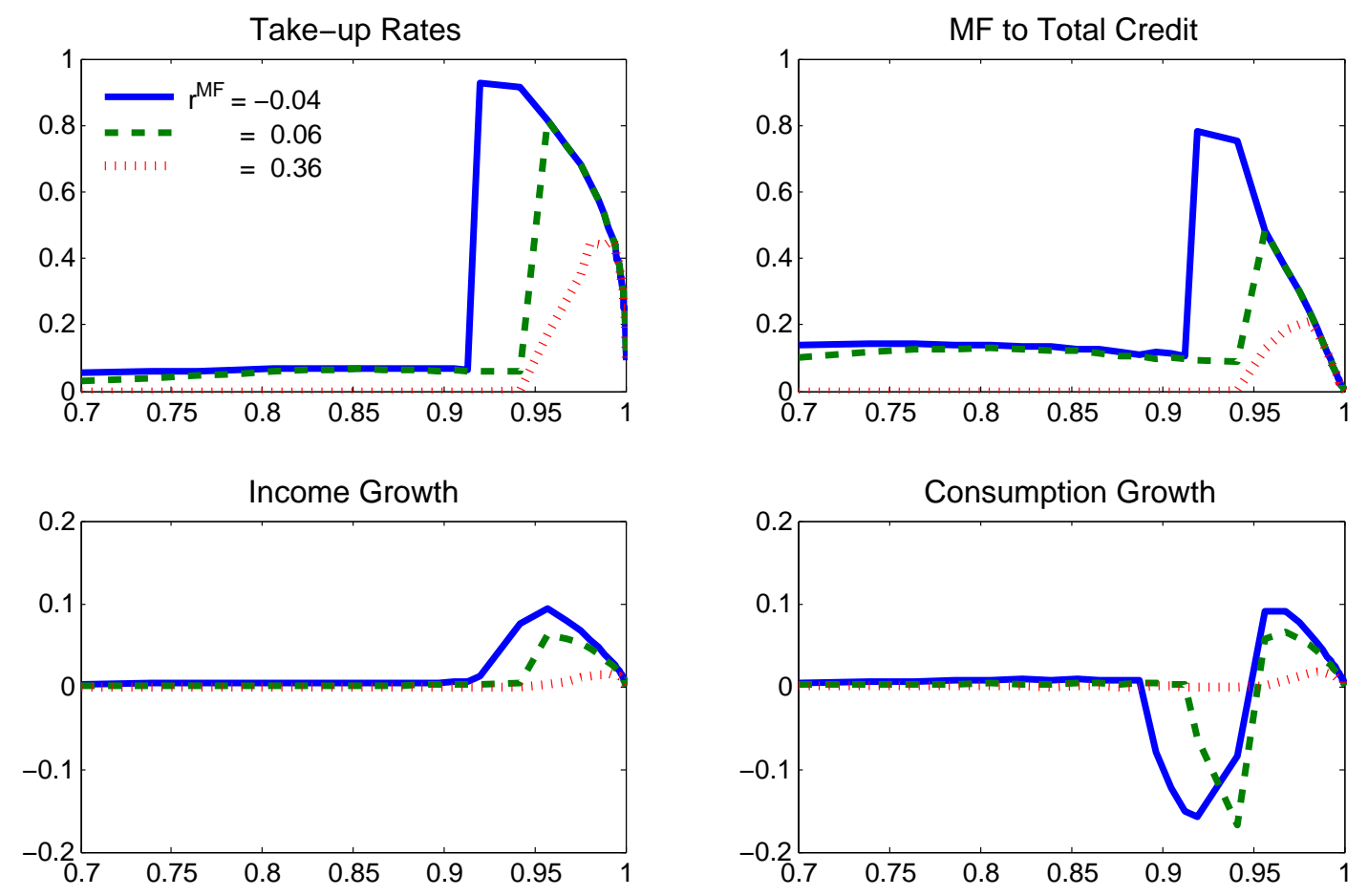

Fig. 3: Short-Run Effect of Microcredit, with Different Lending Rates

increases in TFP leading to small changes in output, but a somewhat larger increase in consumption. For the case, with high interest rates, even these modest impacts all but disappear.

Figure 3 gives more insights into these patterns. It plots take up rates, microcredit as a fraction of total credit, and impacts on income and consumption at different percentiles of the entrepreneurial ability $(z)$ distribution for microcredit with different lending rates. The figure crystallizes the heterogeneous impacts in the model. At all interest rates, borrowing and impacts are concentrated near the higher end of the ability distribution, but as interest rates increase, take up falls and becomes even more concentrated near the top (top left panel). Microcredit relative to total credit shows even sharper declines as interest rates increase, showing that the intensive margin also responds negatively (top right panel). The lower panels show that the impacts on income and consumption are even more muted than those on credit.

In sum, higher interest rates, as expected, dampen the effects of microfinance, bringing the short-run investment and entrepreneurship predictions closer to the existing empirical evidence on the effect of microfinance reviewed in Table 3. Another implication is the stronger positive selection in who uses microloans. As shown in Figure 3, the higher the lending rates, 
the more concentrated the effect of microfinance at the top of the entrepreneurial ability distribution.

\section{Concluding Remarks}

We first reviewed the empirical evidence on the effect of asset grants and microcredit programs and then showed how these findings, to the extent that a pattern exists, can be explained by a model in which agents make optimal decisions subject to financial frictions. The simplest model underestimated the impact of asset grants in the short run and overestimated that of microfinance, although the microfinance results were more comparable to the estimates from village funds programs. We first conjecture that a modified version of our model with technical training, a common element of real-world asset grant programs, can replicate the empirical evidence on asset grants. We then show that introducing realistic levels of spreads between lending and deposit rates makes the model short run results align with the empirical evaluations of microfinance. A central finding from both empirical and quantitative research is the lack of dramatic escapes from poverty traps.

Because the empirical studies are small-scale relative to the overall economy, and the followups are performed at most a few years after the program implementation, we only learn from them short run, partial equilibrium outcomes. Having a fully specified equilibrium model allows us to consider the macro-level effect of scaled up programs and also over a longer time horizon. We find that it would be erroneous to simply extrapolate the short run PE empirical results to predict long run GE effects. While one-time asset grant programs hold a lot of promise based on the empirical evidence, the model shows that it has negligible longer run effects, since the economy, absent any other permanent change, will revert eventually to its unique invariant distribution. On the other hand, while microcredit programs in the real world have low take-up rates and small overall impact, the model shows that, once they are scaled up, through the increase in wage, even non-borrowers will be positively affected by the programs, consistent with village funds programs that showed local labor market equilibrium effect. Again, neither intervention leads to escapes from poverty traps, even when scaled up to the full economy.

More broadly, we see large gains from trade between micro and macro development. The well-established micro-experimental evidence helps us enhance theoretical models, while quantitative theory is a natural guide to interpreting the micro-evidence and making predictions on what can be expected when existing programs are scaled up over time. 


\section{References}

Aghion, P. And P. Bolton (1997): "A Theory of Trickle-Down Growth and Development," Review of Economic Studies, 64, 151-172.

Angelucci, M., D. Karlan, And J. Zinman (2015): "Microcredit Impacts: Evidence from a Randomized Microcredit Program Placement Experiment by Compartamos Banco," American Economic Journal: Applied Economics, 7, 151-82.

Attanasio, O., B. Augsburg, R. De Haas, E. Fitzsimons, and H. Harmgart (2015): "The Impacts of Microfinance: Evidence from Joint-Liability Lending in Mongolia," American Economic Journal: Applied Economics, 7, 90-122.

Augsburg, B., R. De Haas, H. Harmgart, and C. Meghir (2015): "The Impacts of Microcredit: Evidence from Bosnia and Herzegovina," American Economic Journal: Applied Economics, 7, 183-203.

Bandiera, O., R. Burgess, N. Das, S. Gulesci, I. Rasul, and M. Sulaiman (2016): "Labor Markets and Poverty in Village Economies," Manuscript.

Baneruee, A., E. Breza, E. Duflo, R. Glennerster, and C. G. Kinnan (2014): "Does Microfinance Foster Business Growth? The Importance of Entrepreneurial Heterogeneity," MIT.

Baneruee, A., E. Duflo, R. Glennerster, and C. Kinnan (2015a): "The Miracle of Microfinance? Evidence from a Randomized Evaluation," American Economic Journal: Applied Economics, 7, 22-53.

Banerjee, A., E. Duflo, N. Goldberg, D. Karlan, R. Osei, W. Parienté, J. Shapiro, B. Thuysbaert, ANd C. Udry (2015b): "A multifaceted program causes lasting progress for the very poor: Evidence from six countries," Science, 348.

Banerjee, A., D. Karlan, And J. Zinman (2015c): "Six Randomized Evaluations of Microcredit: Introduction and Further Steps," American Economic Journal: Applied Economics, 7, 1-21.

Banerjee, A. V., E. Duflo, R. Chattopadhyay, and J. Shapiro (2011): "Targeting the Hardcore Poor: An Impact Assesstment," Unpublished manuscript, Massachusetts Institute of Technology.

Banerjee, A. V. And B. Moll (2010): "Why Does Misallocation Persist?" American Economic Journal: Macroeconomics, 2, 189-206. 
BanerJee, A. V. And A. F. Newman (1993): "Occupational Choice and the Process of Development," Journal of Political Economy, 101, 274-298.

Blattman, C., N. Fiala, And S. Martinez (2014): "Generating Skilled SelfEmployment in Developing Countries: Experimental Evidence from Uganda," The Quarterly Journal of Economics, 129, 697-752.

Blattman, C., E. P. Green, J. Jamison, M. C. Lehmann, and J. Annan (2016): "The Returns to Microenterprise Support among the Ultrapoor: A Field Experiment in Postwar Uganda," American Economic Journal: Applied Economics, 8, 35-64.

Bleakley, H. And J. P. Ferrie (2013): "Up from Poverty? The 1832 Cherokee Land Lottery and the Long-run Distribution of Wealth," NBER Working Papers 19175, National Bureau of Economic Research, Inc.

Breza, E. And C. Kinnan (2016): "Measuring the Equilibrium Impacts of Credit: Evidence from the Indian Microfinance Cisis," Manuscript, Northwestern University.

Buera, F. J. (2008): "Persistency of Poverty, Financial Frictions, and Entrepreneurship," Unpublished manuscript, Northwestern University.

Buera, F. J., J. P. Kaboski, And Y. Shin (2011): "Finance and Development: A Tale of Two Sectors," American Economic Review, 101, 1964-2002.

- (2012): "The Macroeconomics of Microfinance," NBER Working Papers 17905, National Bureau of Economic Research, Inc.

- (2014): "Macro-Perspective on Asset Grants Programs: Occupational and Wealth Mobility," American Economic Review, 104, 159-64.

- (2015): "Entrepreneurship and Financial Frictions: A Macrodevelopment Perspective," Annual Review of Economics, 7, 409-436.

Buera, F. J. And Y. Shin (2013): "Financial Frictions and the Persistence of History: A Quantitative Exploration," Journal of Political Economy, 121, 221 - 272.

Cai, S., A. Park, And S. Wang (2016): "Microfinance Can Raise Incomes: Evidence from a Randomized Control Trial in China," Tech. rep., HKUST.

Crépon, B., F. Devoto, E. Duflo, and W. Parienté (2015): "Estimating the Impact of Microcredit on Those Who Take It Up: Evidence from a Randomized Experiment in Morocco," American Economic Journal: Applied Economics, 7, 123-50. 
De Mel, S., D. McKenzie, And C. Woodruff (2008): "Returns to Capital in Microenterprises: Evidence from a Field Experiment," Quarterly Journal of Economics, 123, $1329-1372$.

De Mel, S., D. McKenzie, And C. Woodruff (2012): "One-Time Transfers of Cash or Capital Have Long-Lasting Effects on Microenterprises in Sri Lanka," Science, 335, 962-966.

Emran, M. S., V. Robano, And S. C. Smith (2014): "Assessing the Frontiers of Ultrapoverty Reduction: Evidence from Challenging the Frontiers of Poverty Reduction/Targeting the Ultra-poor, an Innovative Program in Bangladesh," Economic Development and Cultural Change, 62, 339-380.

Fafchamps, M., D. McKenzie, S. Quinn, And C. Woodruff (2013): "Microenterprise Growth and the Flypaper Effect: Evidence from a Randomized Experiment in Ghana," Tech. rep., University of Oxford.

Field, E. AND R. PANDE (2008): "Repayment Frequency and Default in Microfinance: Evidence From India," Journal of the European Economic Association, 6, 501-509.

Field, E., R. Pande, J. Papp, And N. Rigol (2013): "Does the Classic Microfinance Model Discourage Entrepreneurship among the Poor? Experimental Evidence from India," American Economic Review, 103, 2196-2226.

Ghatak, M. And N.-H. JiAng (2002): "A simple model of inequality, occupational choice, and development," Journal of Development Economics, 69, 205-226.

Giné, X. And R. M. Townsend (2004): "Evaluation of Financial Liberalization: A General Equilibrium Model with Constrained Occupation Choice," Journal of Development Economics, 74, 269-307.

Greaney, B., J. P. Kaboski, and E. V. Leemput (2016): "Can Self-Help Groups Really Be "Self-Help"?" Review of Economic Studies, forthcoming.

Haushofer, J. And J. Shapiro (2013): "Household Response to Income Changes: Evidence from an Unconditional Cash Transfer Program in Kenya," Tech. rep., Abdul Latif Jameel Poverty Action Lab.

Kaboski, J. And R. Townsend (2005): "Policies and Impact: An Analysis of VillageLevel Microfinance Institutions," Journal of the European Economic Association, 3, 1-50. 
_ (2011): "A Structural Evaluation of a Large-Scale Quasi-Experimental Microfinance Initiative," Econometrica, 79, 1357-1406.

Kaboski, J. P., M. Lipscomb, and V. Midrigan (2014): "The Aggregate Impact of Household Saving and Borrowing Constraints: Designing a Field Experiment in Uganda," American Economic Review, 104, 171-76.

Kaboski, J. P. And R. M. Townsend (2012): "The Impact of Credit on Village Economies," American Economic Journal: Applied Economics, 4, 98-133.

Karlan, D., R. Knight, And C. Udry (2015): "Consulting and Capital Experiments with Microenterprise Tailors in Ghana," Journal of Economic Behavior and Organization, $118,281-302$.

Karlan, D. And J. Zinman (2010): "Expanding Credit Access: Using Randomized Supply Decisions to Estimate the Impacts," Review of Financial Studies, 23, 433-464.

- (2011): "Microcredit in Theory and Practice: Using Randomized Credit Scoring for Impact Evaluation," Science, 332, 1278-1284.

Lucas, Robert E, J. (1993): "Making a Miracle," Econometrica, 61, 251-72.

Matsuyama, K. (2011): "Imperfect Credit Markets, Household Wealth Distribution, and Development," Annual Review of Economics, 3, 339-362.

McKenzie, D. And C. Woodruff (2008): "Experimental Evidence on Returns to Capital and Access to Finance in Mexico," World Bank Economic Review, 22, 457-482.

McKenzie, D. J. (2016): "Identifying and Spurring High-Growth Entrepreneurship: Experimental Evidence from a Business Plan Competition," Manuscript, World Bank.

Mold, B. (2014): "Productivity Losses from Financial Frictions: Can Self-financing Undo Capital Misallocation?" American Economic Review, 104, 3186-3221.

Morduch, J., S. Ravi, And J. Bauchet (2012): "Failure vs. Displacement: Why An Innovative Anti-Poverty Program Showed No Net Impact," Discussion Paper Series 32, PRIMCED.

Piketty, T. (1997): "The Dynamics of the Wealth Distribution and the Interest Rate with Credit Rationing," Review of Economic Studies, 64, 173-189.

Tarozzi, A., J. Desai, and K. Johnson (2015): "The Impacts of Microcredit: Evidence from Ethiopia," American Economic Journal: Applied Economics, 7, 54-89. 